\title{
Improvement in the Symptoms and VEGF Levels after Resection of an Extrame Dullary Spinal Tumor and Additional Chemotherapy in a Patient with Multiple Myeloma Complicated with POEMS Syndrome
}

\author{
Mariko Sano ${ }^{1}$, Tatou Iseki ${ }^{1}$, Makoto Sasaki ${ }^{2}$, Yutaka Tsukune ${ }^{2}$, Hajime Yasuda ${ }^{2}$, \\ Kazo Kanazawa ${ }^{1}$, Atsushi Arakawa ${ }^{3}$, Kazumasa Yokoyama ${ }^{1}$, Norio Komatsu ${ }^{2}$, \\ Nobutaka Hattori ${ }^{1}$ and Kenya Nishioka ${ }^{1}$
}

\begin{abstract}
:
We herein report a case of multiple myeloma and polyneuropathy, organomegaly, endocrinopathy, myeloma protein, and skin changes (POEMS) syndrome. The patient experienced exacerbated gait disturbance due to weakness and numbness in the lower limbs. Thoracic magnetic resonance imaging revealed an extramedullary tumor with spinal compression that required surgical resection. Plasmacytoma was diagnosed based on a biopsy. Radiation, betamethasone, and chemotherapy were therefore administered. Surgical removal of extramedullary tumors improved his symptoms, motor conduction velocity, and amplitude of the muscle action potential in the peroneal and tibial nerves, as shown by the nerve conduction study. Surgery also decreased the serum vascular endothelial growth factor levels. The patient required additional chemotherapy due to multiple myeloma and showed better outcomes nine months after discharge. The benefits of some treatments remain controversial due to the small number of patients. However, our findings reveal that an early diagnosis and comprehensive treatment may result in better outcomes in such patients.
\end{abstract}

Key words: POEMS syndrome, multiple myeloma, VEGF, osteolysis, osteosclerosis

(Intern Med 60: 3625-3630, 2021)

(DOI: 10.2169/internalmedicine.6929-20)

\section{Introduction}

Patients with polyneuropathy, organomegaly, endocrinopathy, myeloma protein, and skin changes (POEMS) syndrome characteristically present with a monoclonal plasma cell disorder, peripheral neuropathy, and one or more of the following symptoms: osteosclerotic myeloma, increased levels of serum vascular endothelial growth factor (VEGF), organomegaly, endocrinopathy, edema, typical skin changes, and papilledema (1). POEMS syndrome is not commonly associated with any specific cancer (1). Multiple myeloma (MM) is characterized by the neoplastic proliferation of plasma cells with monoclonal immunoglobulins and oste- olytic bone lesions (2). POEMS syndrome, MM, and plasmacytoma are rarely present simultaneously.

We herein report a patient with POEMS syndrome complicating MM whose outcome improved after multiple treatments.

\section{Case Report}

This study was approved by the ethics committee of the Juntendo University School of Medicine.

A 51-year-old man with a history of cholelithiasis developed edema in both legs. Seven months later, he developed a low-grade fever and numbness in his legs, which progressed to muscle weakness. He was admitted to a hospital

${ }^{1}$ Department of Neurology, Juntendo University School of Medicine, Japan, ${ }^{2}$ Department of Hematology, Juntendo University School of Medicine, Japan and ${ }^{3}$ Department of Human Pathology, Juntendo University School of Medicine, Japan

Received for publication December 16, 2020; Accepted for publication April 15, 2021

Correspondence to Dr. Kenya Nishioka, nishioka@juntendo.ac.jp 
Table 1. Results of Nerve Conduction Study before and after Treatment.

\begin{tabular}{ccccccc}
\hline \multirow{2}{*}{ Nerve } & \multirow{2}{*}{ Site } & & $\begin{array}{c}\text { Limit of } \\
\text { normal values }\end{array}$ & Day 2 & Day 48 & Day 271 \\
\hline \multirow{2}{*}{ Median N. (right) } & \multirow{2}{*}{ Wrist-elbow } & MCV & $>48 \mathrm{~m} / \mathrm{s}$ & 50.7 & 44.3 & 52.6 \\
& & Amp & $>5 \mathrm{mV}$ & 3.39 & 9.42 & 3.73 \\
& & DL & $<4.5 \mathrm{~ms}$ & 4.14 & 4.14 & 3.9 \\
& & FWL & $<31.4 \mathrm{~ms}$ & 33.5 & 24.4 & 26.2 \\
\hline \multirow{2}{*}{ Ulnar N. (right) } & \multirow{2}{*}{ Wrist-below groove } & MCV & $>46 \mathrm{~m} / \mathrm{s}$ & 51.9 & 47.0 & 57.5 \\
& & Amp & $>4.7 \mathrm{mV}$ & 4.89 & 6.48 & 6.16 \\
& & DL & $<3.6 \mathrm{~ms}$ & 6.57 & 7.35 & 2.97 \\
& & FWL & $<31.7 \mathrm{~ms}$ & 31.3 & 30.9 & 30.6 \\
\hline Peroneal N. (left) & Ankle-head of fibula & MCV & $>37.1 \mathrm{~m} / \mathrm{s}$ & 35.6 & 31.5 & 40 \\
& & Amp & $>0.7 \mathrm{mV}$ & 0.93 & 1.4 & 2.68 \\
& & DL & $<6.2 \mathrm{~ms}$ & 4.55 & 5.85 & 3.8 \\
& & FWL & $<55.3 \mathrm{~ms}$ & 75.8 & 68.1 & 55.2 \\
\hline Tibial N. (left) & \multirow{2}{*}{ Ankle-popliteal } & MCV & $>36 \mathrm{~m} / \mathrm{s}$ & 36.4 & 33 & 39.8 \\
& & Amp & $>5.6 \mathrm{mV}$ & 4.15 & 2.63 & 8.24 \\
& & DL & $<5.9 \mathrm{~ms}$ & 6.15 & 5.85 & 4.5 \\
& & FWL & $<56.8 \mathrm{~ms}$ & 74.5 & 68.7 & 56.6 \\
\hline
\end{tabular}

N.: nerve, MCV: motor conduction velocity, Amp: amplitude of the muscle action potential on wrist or ankle stimulation, DL: distal latency, FWL: F wave minimum latency on wrist or ankle stimulation, R: right, L: left, NA: not assessed

nine months after the onset of the edema.

On admission, he had mild distension of the abdomen, pitting edema of his legs, and dark-red pigmentation throughout the body, including his face. He had severe gait disturbance due to proximal muscle weakness in his legs and upper arms. Manual muscle testing indicated a score of $3 / 3$ (right/left) of the iliopsoas and $3 / 3$ of the quadriceps. Other muscles showed no weakness in the manual muscle test. His deep tendon reflexes in the upper and lower limbs decreased bilaterally, without the appearance of pathological reflexes. He had severe pain in both shoulders, a subjective feeling of warmth, a lack of deep sensation in the T6-S1 dermatomes, and a reduced sense of touch in the L4-S1 dermatomes. He reported that he was constipated and experienced frequent micturition.

Blood biochemistry revealed elevated levels of serum VEGF (3,350 pg/mL, mean: 220, range: $62-707 \mathrm{pg} / \mathrm{mL})$ and high levels of a monoclonal immunoglobulin $\mathrm{G}$ lambda-type protein. He had normal serum calcium $(9.5 \mathrm{mg} / \mathrm{dL}$, normal: 8.8-10.6 mg/dL), low serum albumin $(2.3 \mathrm{~g} / \mathrm{dL}$, normal: 4.0$5.2 \mathrm{~g} / \mathrm{dL})$, and elevated beta- 2 microglobulin $(3.4 \mathrm{mg} / \mathrm{L}$, normal: 0.8-2.4 mg/dL) levels. An examination of his cerebrospinal fluid revealed an elevated protein level $(1,191 \mathrm{mg} / \mathrm{dL})$ and 6 mononuclear cells/mL. A nerve conduction study on day 2 revealed a low-amplitude signal in the right median nerve and decreased conduction velocities of both peroneal and tibial nerves (Table 1).

Abdominal computed tomography (CT) revealed hepatomegaly (Fig. 1A). Thoracic CT of the bone showed osteolysis at the T2-T4 level (Fig. 1B) and multiple osteosclerotic nodules in the thoracic vertebrae (Fig. 1C). Magnetic resonance imaging of the thoracic spine showed a solid ex- tramedullary tumor at the T2-T4 level (Fig. 1D) that surrounded the spinal canal and was compressing the spinal parenchyma (Fig. 1E). Positron emission tomography-CT showed no metastases to other organs (Fig. 1F). These findings met the diagnostic criteria of POEMS syndrome (1).

The tumor and vertebral arch were resected on Day 4 to relieve the spinal compression. Histological findings revealed the tumor to be a plasmacytoma positive for lambda protein on staining (Fig. 2). His symptoms improved after the surgery, and he was able to walk with a cane. His shoulder pain and edema in the lower legs also improved, but the numbness and loss of sensation persisted. His serum level of VEGF decreased from 3,350 pg/mL to $558 \mathrm{pg} / \mathrm{mL}$ (Fig. 3). A follow-up nerve conduction study showed an improvement in the amplitude of the right median nerve (Table 1). Bone marrow aspiration and a biopsy conducted on day 23 were normal. We diagnosed our patient with MM based on the extramedullary plasmacytoma and multiple osteolysis, according to the standard criteria (3). His MM was categorized as stage 2 according to the international staging system and stage 3 according to the Durie-Salmon staging system (2). These findings confirmed the diagnosis of MM accompanied by POEMS syndrome.

Our patient did not have evidence of metastases to other organs or disseminated bone marrow involvement. We treated him with radiation therapy (total 24 Gy) and oral betamethasone (starting at $3 \mathrm{mg}$ and decreasing by $1 \mathrm{mg}$ every 3 days) to relieve the spinal compression. He was discharged from the hospital on day 52. His modified Rankin Scale on discharge had decreased from 5 to 2 (Fig. 3). We administered additional treatment with bortezomib, lenalidomide, and dexamethasone after discharge. Nine months after 

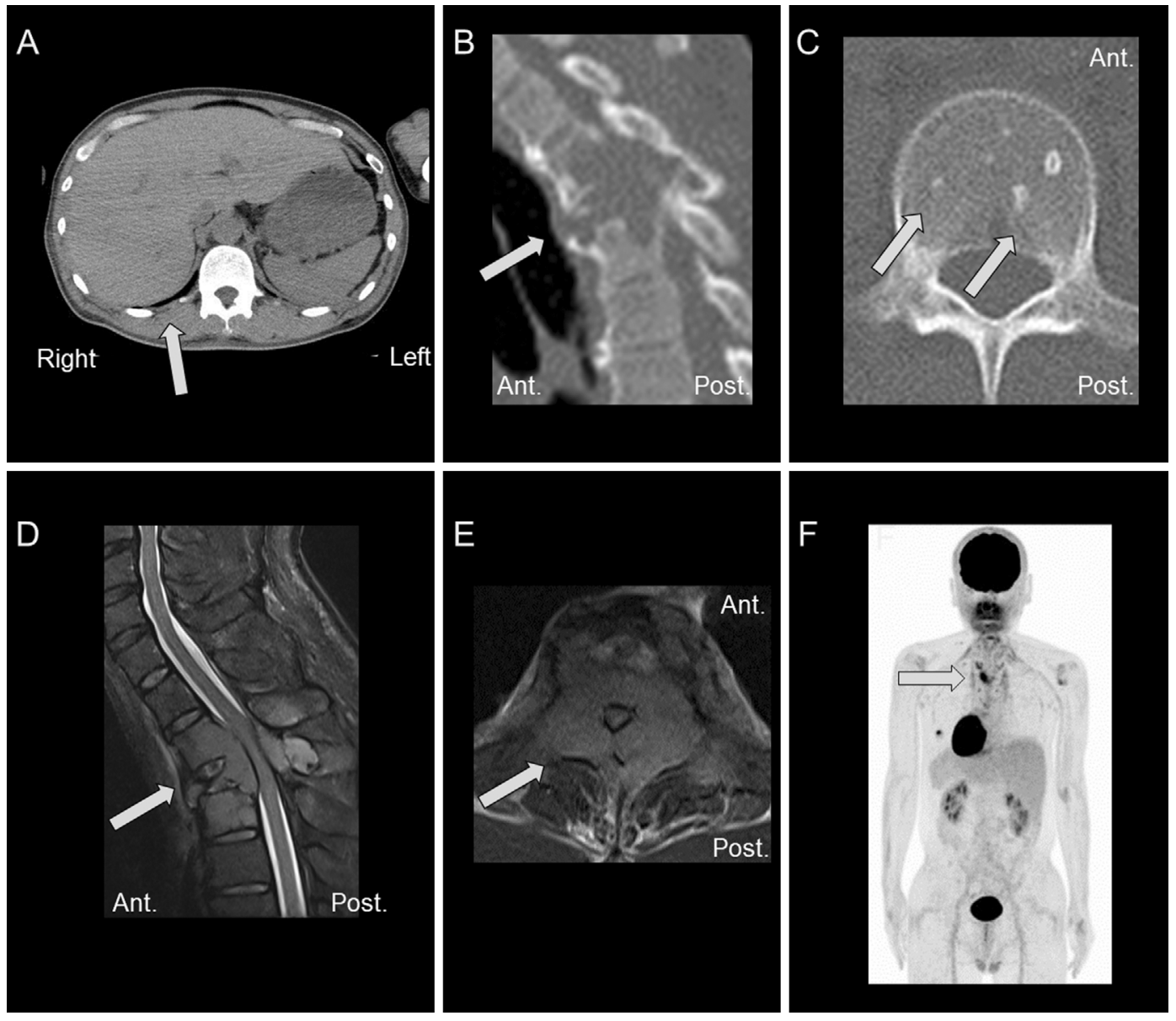

Figure 1. Imaging, pathological findings, and a schematic illustration of the prognosis during the admission of the patient. (A) Abdominal computed tomography (CT) showing hepatomegaly (white arrow). (B) Thoracic vertebral CT (axial view) showing osteolysis in the thoracic vertebrae T2-T4. (C) Thoracic vertebral CT (coronal view) showing multiple osteosclerotic nodules in the thoracic vertebrae. (D) Magnetic resonance imaging (MRI) of the spine (sagittal view) showing an extramedullary tumor at T2-T4. (E) MRI of the spine (axial view) showed that it was surrounded by the tumor (white arrow), and (F) positron emission tomography-CT did not show any metastases in other organs.

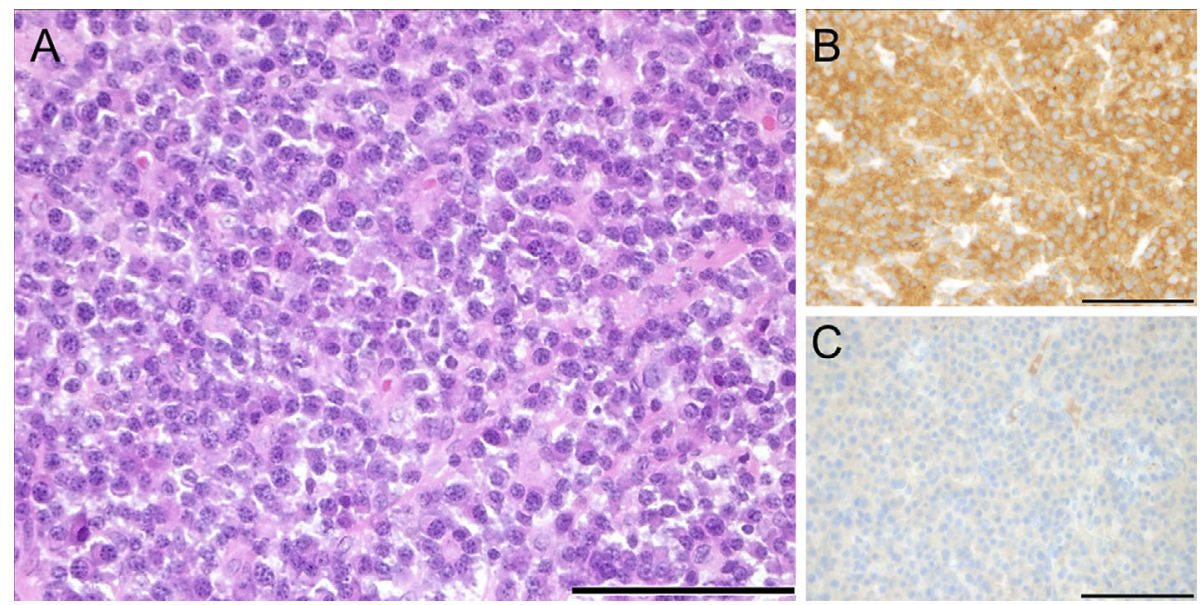

Figure 2. Histology of the excised tumor. (A) Hematoxylin and Eosin staining section showing neoplastic proliferation of atypical plasmacytes, consistent with a plasmacytoma. (B) Immuno-stained section strongly positive for lambda light chains. (C) Immuno-stained section weakly positive for kappa light chains. The length of each bar is $100 \mu \mathrm{m}$. 


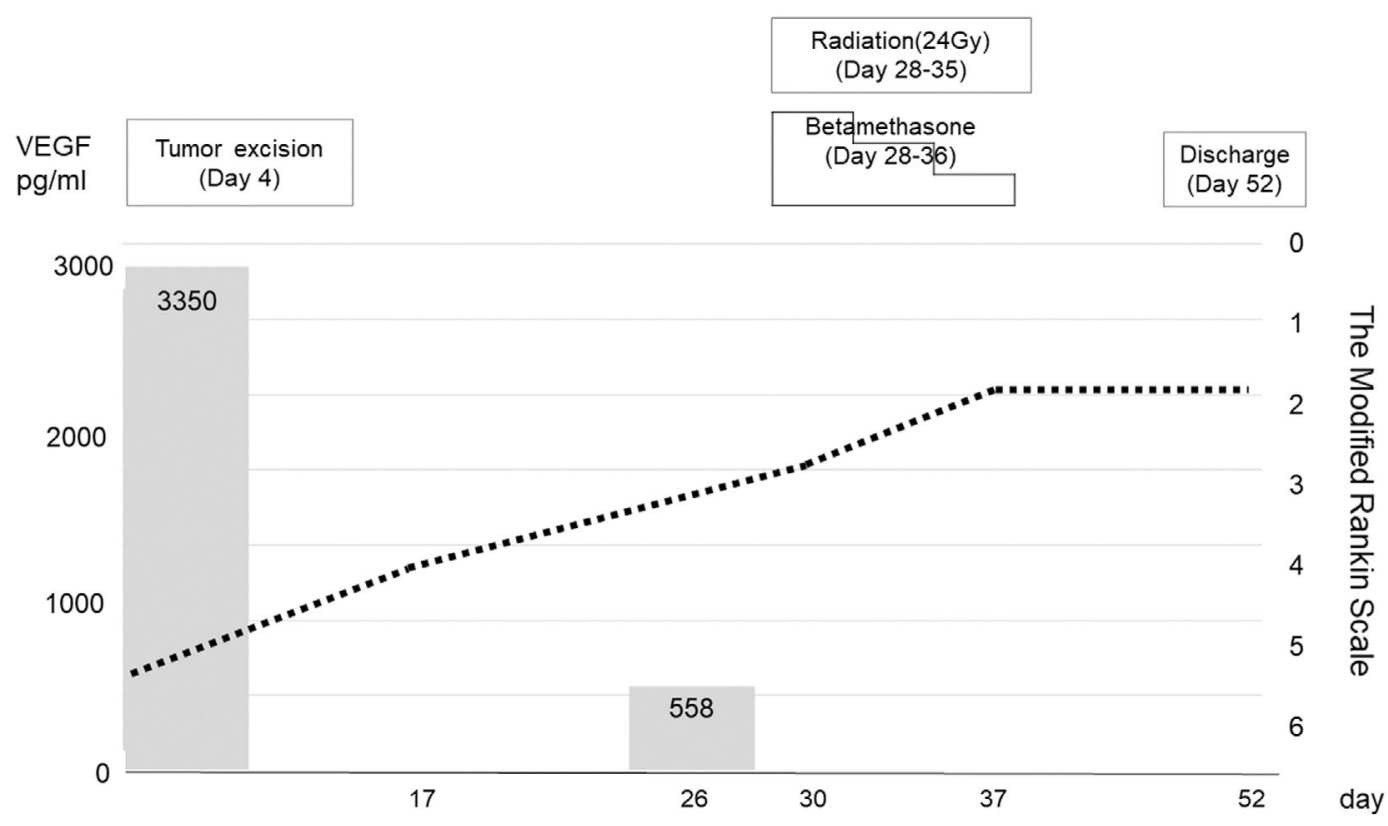

Figure 3. A schematic illustration of the clinical course of our patient. The bar graph shows the vascular endothelial growth factor levels on Days 1 and 26. The Modified Rankin Scale shows the favorable outcome after comprehensive treatment including surgery, radiation, and steroid therapy.

the onset of the disease, he was able to walk unaided and had no weakness or sensory disturbance in his limbs. According to the response criteria definition, he exhibited a very good partial response (4). Our follow-up nerve conduction study indicated the improvements of motor conduction velocity and amplitude of the muscle action potential in the peroneal and tibial nerves. Those of the median and ulnar nerves showed no changes at days 48 or 217 (Table 1).

\section{Discussion}

Our patient had an extramedullary solid tumor which was pathologically diagnosed to be plasmacytoma in the spine, multiple osteolytic lesions, and symptoms related to POEMS syndrome, such as osteosclerosis, hepatomegaly, polyneuropathy, skin lesion, and secretion of M protein. Furthermore, this case was complicated with lesions of both osteolysis and osteosclerosis. Thus, our patient met the standard criteria for both MM and POEMS syndrome. There are four types of bone lesions in MM: solitary lesions (plasmacytoma), diffuse skeletal lesions (myelomatosis), diffuse skeletal osteopenia, and osteosclerotic myeloma (5). Osteosclerosis is commonly seen in patients with POEMS syndrome (1). Some patients with POEMS syndrome have a complex form of osteolysis and osteosclerosis, with a prevalence of $31-59 \%$ (6). We therefore considered our patient to have MM complicated by POEMS syndrome.

To date, multiple cases of POEMS syndrome associated with plasmacytoma have been reported (1). Approximately $11 \%$ to $24 \%$ of patients with MM have complications of spinal cord compression (7). Such patients characteristically present with back pain, radicular pain, sensory-motor disturbances, and bladder and rectal disturbances (7). We com- pared four cases of MM complicated by POEMS syndrome reported previously (Table 2) (8-11). Including our case, all five reported cases had a middle-aged onset, gait disturbance, and numbness in the lower limbs at the onset. Symptoms related to POEMS syndrome and findings of plasmacytoma in the bone marrow aspirate were also observed in these cases. Three of the five patients were pathologically diagnosed with plasmacytoma, and three of the five patients had a solid tumor in the thoracic spine. In our patient, only surgical resection was performed for the tumor, with a decrease in the VEGF level being noted after surgery. In two previous cases with thoracic tumors, surgical intervention could not be performed due to metastasis or severe coagulopathy $(8,10)$. For cases of solitary and localized thoracic plasmacytoma, early surgical resection may be effective.

Spinal cord compression may be due to extension of the extramedullary tumor, as observed in our patient. Our case showed improvement in his gait ability after the operation. A nerve conduction study showed relatively mild findings of demyelination in the lower limbs compared to previous reports of 38 patients with POEMS syndrome (12). Thus, the gait disturbance in our patient is thought to have been due to myelopathy. These findings suggested there is some benefit to early intervention with tumor resection. Regarding bone lesions, osteosclerotic lesions were observed as multiple nodules with a size of a few millimeters. Nearly $30 \%$ of osteosclerotic lesions are not identifiable on roentgenography (13). Thus, it may be useful to evaluate the lesions using two methods: roentgenography and CT with bone window settings.

Regarding treatment, patients with MM can be treated with palliative chemotherapy or prednisone (3). Patients with POEMS syndrome may respond to radiotherapy, melphalan- 
Table 2. Cases of Multiple Myeloma Complicated by POEMS Syndrome.

\begin{tabular}{|c|c|c|c|c|c|}
\hline Reference & Our case & 8 & 9 & 10 & 11 \\
\hline Sex / Age at onset & Man / 51 & Man / 51 & Woman / 42 & Man / 52 & Man / 72 \\
\hline Country & Japan & US & Japan & India & Greece \\
\hline Initial symptoms & $\begin{array}{l}\text { Numbness in the } \\
\text { lower limbs and } \\
\text { gait disturbance }\end{array}$ & $\begin{array}{l}\text { Numbness in the } \\
\text { lower limbs and } \\
\text { gait disturbance }\end{array}$ & $\begin{array}{l}\text { Numbness in the } \\
\text { lower extremities } \\
\text { and gait distrubance }\end{array}$ & $\begin{array}{l}\text { Weakness in the } \\
\text { lower limbs }\end{array}$ & $\begin{array}{c}\text { Fatigue, muscle } \\
\text { weakness, skin } \\
\text { changes, and dyspnea }\end{array}$ \\
\hline Multiple neuropathy & Yes & Yes & Yes & Yes & Yes \\
\hline Organ enlargement & Yes & Yes & Yes & Yes & Yes \\
\hline Endocrine disorders & Yes & Yes & No & No & No \\
\hline M protein & Yes & Yes & Yes & Yes & Yes \\
\hline Skin disorders & Yes & No & No & No & Yes \\
\hline Osteosclerotic lesions & Yes & Yes & No & No & No \\
\hline Osteolytic lesions & Yes & Yes & No & Yes & No \\
\hline Location of tumor & Thoracic spine & Thoracic spine & No & Thoracic spine & No \\
\hline Bone marrow aspirate & Normal & $\begin{array}{l}\text { Immature plasma } \\
\text { cells increase }\end{array}$ & $\begin{array}{l}\text { Hypercellular with } \\
\text { massive plasma cell } \\
\text { proliferation }\end{array}$ & $\begin{array}{l}\text { Diffuse neoplastic } \\
\text { plasma cell } \\
\text { proliferation }\end{array}$ & $\begin{array}{l}\text { Slighlty increased } \\
\text { plasma cells }\end{array}$ \\
\hline Pathological diagnosis & Plasmacyoma & Unknown & $\begin{array}{l}\text { Plasma cell } \\
\text { myeloma }\end{array}$ & Plasmacytoma & No \\
\hline Treatment & $\begin{array}{l}\text { Operation and } \\
\text { radiation }\end{array}$ & Plasmapheresis & $\begin{array}{c}\text { Epoprostenol } \\
\text { sodium, sildenafil } \\
\text { citrate and bosentan } \\
\text { hydrate for } \\
\text { Pulmonary } \\
\text { hypertension }\end{array}$ & $\begin{array}{l}\text { Chemotherapy } \\
\text { and prednisolone }\end{array}$ & $\begin{array}{l}\text { Cyclophosphamide, } \\
\text { corticosteroides, } \\
\text { lenalidomide }\end{array}$ \\
\hline $\begin{array}{l}\text { Activity of daily living } \\
\text { (follow-up days) }\end{array}$ & $\begin{array}{l}\text { Ameliorated } \\
\text { (nine months) }\end{array}$ & No improvement & Death & Death & Improved (one year) \\
\hline $\begin{array}{l}\text { VEGF }(\mathrm{pg} / \mathrm{mL}) \\
\text { (before treatment) } \\
(\text { mean } 220,62-707)\end{array}$ & 3,350 & Unmeasured & Unmeasured & Unmeasured & Unmeasured \\
\hline $\begin{array}{l}\text { VEGF }(\mathrm{pg} / \mathrm{mL}) \\
\text { (after treatment) }\end{array}$ & 558 & Unmeasured & Unmeasured & Unmeasured & Unmeasured \\
\hline
\end{tabular}

VEGF: vascular endothelial growth factor

dexamethasone, corticosteroids, or hematopoietic cell transplantation (1). Our patient had an improved outcome after receiving multiple treatments, including tumor resection. Surgery alone was able to improve the symptoms and led to a decrease in the VEGF level. The VEGF levels were generally not assessed in the previous reports (Table 2). Our case first showed a decrease in the VEGF level after the operation. Therefore, monitoring the VEGF levels may aid in the evaluation of the effectiveness of the treatment. The VEGF levels may reflect the clinical severity.

In addition, our follow-up nerve conduction study indicated partial improvements in the peroneal and tibial nerves. The treatments seemingly affected the peripheral nerves as well. However, three of four previous cases showed no improvement or death even after multiple treatments. Patients $\geq$ 51 years old with myeloma reportedly showed a significantly shorter survival than those $\leq 50$ years old among 10,549 patients (14). Of note, the 10 -year survival rate was $19 \%$ after conventional therapy (14). Thus, our patient will require further follow-up along with comprehensive treatments.

In conclusion, our findings suggest that an early diagnosis and comprehensive treatment may result in a better outcome in such patients.
Author's disclosure of potential Conflicts of Interest (COI). Kenya Nishioka: Research funding, Biogen Japan.

\section{References}

1. Dispenzieri A. POEMS syndrome: 2019 update on diagnosis, riskstratification, and management. Am J Hematol 94: 812-827, 2019.

2. Greipp PR, San Miguel J, Durie BG, et al. International staging system for multiple myeloma. J Clin Oncol 23: 3412-3420, 2005.

3. Rajkumar SV, Dimopoulos MA, Palumbo A, et al. International Myeloma Working Group updated criteria for the diagnosis of multiple myeloma. Lancet Oncol 15: e538-548, 2014.

4. Durie BG, Harousseau JL, Miguel JS, et al. International uniform response criteria for multiple myeloma. Leukemia 20: 1467-1473, 2006.

5. Raza S, Leng S, Lentzsch S. The critical role of imaging in the management of multiple myeloma. Curr Hematol Malig Rep 12: 168-175, 2017.

6. Clark MS, Howe BM, Glazebrook KN, Mauermann ML, Broski SM. Osteolytic-variant POEMS syndrome: an uncommon presentation of "osteosclerotic" myeloma. Skeletal Radiol 46: 817-823, 2017.

7. Cawley DT, Butler JS, Benton A, et al. Managing the cervical spine in multiple myeloma patients. Hematol Oncol 37: 129-135, 2019.

8. Hyman BT, Westrick MA. Multiple myeloma with polyneuropathy and coagulopathy. A case report of the polyneuropathy, or- 
ganomegaly, endocrinopathy, M-protein, and skin change (POEMS) syndrome. Arch Intern Med 146: 993-994, 1986.

9. Chinen K, Fujioka Y. Severe pulmonary hypertension caused by smoldering plasma cell myeloma: an autopsy case of POEMS syndrome. Case Rep Med 2012: 836893, 2012.

10. Pal P, Ray S, Guha P, Patra SK, Das KK. Pure motor axonal neuropathy, organomegaly, impaired glucose tolerance, $\mathrm{M}$ protein, skin changes, multiple plasmacytomas \& acute interstitial nephritis in osteolytic myeloma: beyond POEMS! Indian J Hematol Blood Transfus 30 (Suppl 1): 115-119, 2014.

11. Solomou EE, Marnellos P, Agathokleous A, Kyriakou G, Georgiou S, Symeonidis A. Reversal of skin changes in smoldering myeloma with clinical presentation of POEMS syndrome with a lenalidomide-based regimen. Ann Hematol 98: 2625-2626, 2019.

12. Liu M, Zou Z, Guan Y, Li J, Zhou D, Cui L. Motor nerve conduc- tion study and muscle strength in newly diagnosed POEMS syndrome. Muscle Nerve 51: 19-23, 2015.

13. Glazebrook K, Guerra Bonilla FL, Johnson A, Leng S, Dispenzieri A. Computed tomography assessment of bone lesions in patients with POEMS syndrome. Eur Radiol 25: 497-504, 2015.

14. Ludwig H, Durie BG, Bolejack V, et al. Myeloma in patients younger than age 50 years presents with more favorable features and shows better survival: an analysis of 10549 patients from the International Myeloma Working Group. Blood 111: 4039-4047, 2008 .

The Internal Medicine is an Open Access journal distributed under the Creative Commons Attribution-NonCommercial-NoDerivatives 4.0 International License. To view the details of this license, please visit (https://creativecommons.org/licenses/ by-nc-nd/4.0/).

(C) 2021 The Japanese Society of Internal Medicine Intern Med 60: 3625-3630, 2021 